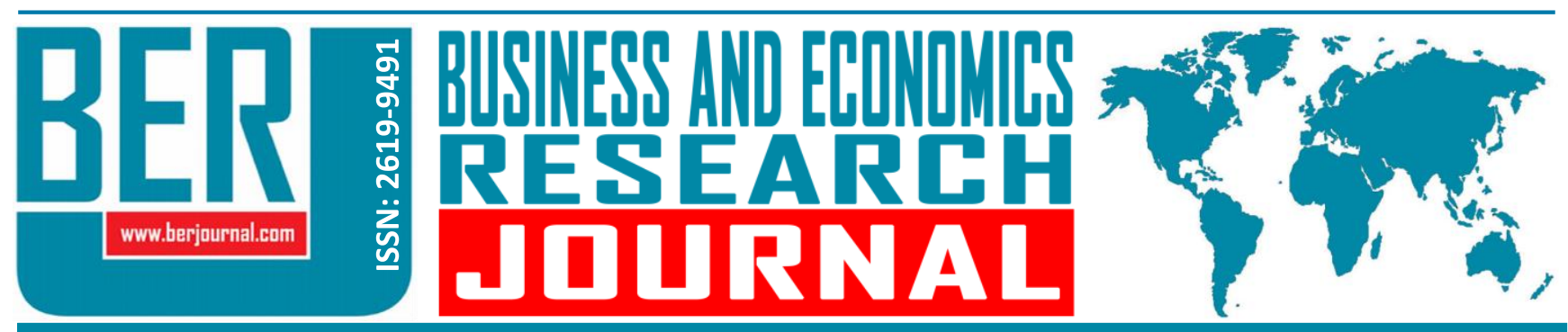

Business and Economics Research Journal Vol. 12, No.4, $2021 \quad$ pp. 799-811

doi: $10.20409 /$ berj.2021.353

\title{
Satın Alma Gücü Paritesi Geçerliliğinin Fourier Birim Kök Testi ile İncelenmesi: N-11 Ülkeleri Örneği
}

\section{Tunahan Haciimamoglu ${ }^{\mathrm{a}}$}

Öz: Satın alma gücü paritesi (SAGP), ülkeler arasında fiyat farklılıklarını ortadan kaldırarak ülkelerin para birimlerinin satın alma gücünü eşitleyen tek fiyat kanununa dayalı bir yaklaşımdır. Uluslararası gelişmişlik ölçütü olarak da kullanılan SAGP hipotezine olan ilgi, ülkelerin karşılaştığı fiyat istikrarsızlıkları ve dış açık sorunları nedeniyle artmaktadır. Artan ilgi ile birlikte SAGP hipotezinin geçerliliği farklı ülke ve ülke gruplarında çeşitli dönem aralıkları itibarıla güncel analiz yöntemleri kullanılarak sınanmaktadır. Bu çalışmanın amacı, dokuz N-11 ülkesinde 1970-2019 dönemi için SAGP hipotezinin geçerliliğini sınamaktır. Bu doğrultuda çalışmada güncel bir test tekniği olarak Lee, Wu ve Yang (2016) tarafından ileri sürülen yatay kesit bağımlılığına, yumuşak kırılmalara ve ortak faktör yapısına izin veren BCIPS birim kök analiz yöntemi kullanılmıştır. Analiz bulgularından N-11 ülkeleri için reel döviz kurlarının durağan olduğu tespit edilmiş, dolayısıyla SAGP hipotezinin geçerli olduğu sonucuna ulaşılmıştır. Bu bağlamda N-11 ülkelerinde reel (efektif) döviz kuru üzerinde şokların etkisinin geçici olduğu, para politikası kararlarında ve uluslararası gelişmişlik ölçütlerinde SAGP'nin güvenilir bir gösterge olarak kullanılabileceği ortaya konulmuştur.

\section{Investigation of the Validity of Purchasing Power Parity with Fourier Unit Root Test: The Case of N-11 Countries}

\begin{abstract}
Purchasing power parity (PPP) is an approach which is based on the law of one price and balances the purchasing power of currencies by excluding price differences among countries. The interest in the PPP hypothesis, which is also used as an international development criteria, has been increasing due to price instability and trade deficits faced by countries. Along with the increasing interest, the validity of the PPP hypothesis is tested more often for different country groups and time periods by using modern analysis methods. The aim of this study is to test the validity of the PPP hypothesis for the period 1970-2019 in nine of N-11 countries. Accordingly, the BCIPS unit root analysis method, which allows for cross-section dependence, soft breaks, and common factor structure and which was proposed by Lee, Wu, and Yang (2016), was used as a modern test technique in the study. The findings of the analysis suggest that the real exchange rates for $\mathrm{N}-11$ countries are stationary, therefore, it is concluded that the PPP hypothesis is valid. In this respect, it is revealed that the effect of shocks on the real (effective) exchange rate in N-11 countries is temporary and that PPP can be used as a reliable indicator in monetary policy decisions and international development measures.
\end{abstract}

Anahtar Sözcükler: Satın Alma Gücü Paritesi, Reel Döviz Kuru, Fourier Birim Kök Testi, Durağanlık, N-11 Ülkeleri

JEL: C23, F31, F41

$\begin{array}{ll}\text { Geliş } & : 09 \text { Haziran } 2021 \\ \text { Düzeltme } & : \text { 28 Temmuz } 2021 \\ \text { Kabul } & : \text { 27 Ağustos } 2021 \\ \text { Tür } & : \text { Araştırma }\end{array}$

Keywords: Purchasing Power Parity, Real Exchange Rate, Fourier Unit Root Test, Stationarity, N-11 Countries

JEL: C23, F31, F41
Received : 09 June 2021

Revised : 28 July 2021

Accepted : 27 August 2021

Type : Research

a Res. Asst., PhD., Recep Tayyip Erdogan University, Faculty of Economics and Administrative Sciences, Department of Economics, Rize, Turkiye, tunahan.haciimamoglu@erdogan.edu.tr (ORCID ID: 0000-0003-1474-8506) 


\section{Giriş}

Satın alma gücü paritesi teorisi, aynı para birimi cinsinden ortak bir mal sepetinin maliyetinin tüm ülkelerde aynı olmasıdır. Başka bir ifade ile sabit bir mal ve hizmet sepeti için herhangi iki ülke arasındaki döviz kurunun, iki ülke fiyat düzeylerinin oranına eşit olması gerektiği anlamına gelmektedir (Strauss, 1995: 991; Chang, 2012: 325). SAGP, mutlak ve nispi olmak üzere iki farklı şekilde açıklanmaktadır. Mutlak SAGP, iki farklı ülke için sepetteki aynı ürün fiyatlarının döviz kuru oranları ile aynı doğrultuda hareket etmesidir. Nispi SAGP ise mal sepetindeki belli bir ürün grubunun zamanla meydana gelen fiyat değişim hareketlerinin döviz kuruna etki etmesi olarak ifade edilmektedir (Balassa, 1964: 584). Bu teorinin altında yatan ana fikir, döviz kuru hareketlerinin büyük ölçüde iç ve dış fiyatlar arasındaki farklardan etkilenmesidir. Bu nedenle, iki ülkedeki satın alma gücünün aynı olması koşulu altında para birimleri arasındaki döviz kurlarının dengede olduğu ileri sürülmektedir. Kısa dönemde sapma olasılığı olmakla birlikte arbitraj mekanizması aracılığı ile döviz kurlarının uzun dönem dengesine ulaşmasının gerekliliğine vurgu yapılmaktadır (Carvalho ve Julio, 2012: 714; Arize, Malindretos ve Ghosh, 2015: 69-70). SAGP kavramı, ilk olarak Geary (1958) tarafından ortaya atılmış ve 1970'lerin başında Khamis (1970) tarafından geliştirilmiştir. Bu kavramın önemi, 1973 yılında Bretton Woods sisteminin çöküşü ve dünyadaki yüksek enflasyon oranları ile giderek artmış ve bu kavrama olan ilgi ise birçok makroekonomik teorinin temelini oluşturmuştur.

SAGP, uluslararası ekonomide değişimin temel ölçütlerinden biri olarak kabul görmektedir. Parite koşulu ise ülkeler arasında mükemmel bir arbitraj mekanizmasının olduğu varsayımına dayanmaktadır (Baum, Barkoulas ve Caglayan, 2001: 379-380). Örneğin Dornbusch (1976), Johnson (1976) ve Lucas (1982) gibi araştırmacılar tarafından birçok teorik ve ampirik çalışmada döviz kurunun belirlenmesi ve modellenmesinde SAGP'yi merkeze alan bir yaklaşım benimsenmektedir. Bu modellerde döviz kurunun uzun dönem denge koşulu olarak muhafaza edilmesi gerektiği vurgulanmakta ancak döviz kurunun kısa dönemde SAGP'den sapması makul karşılanmaktadır. İşlem maliyetleri, vergilendirme, sübvansiyonlar, üretim faktörleri üzerindeki kısıtlamalar, dış ticaret engelleri, ticarete konu olmayan malların varlığı, eksik rekabet koşulları, döviz piyasasına yapılan müdahaleler ve ülkeler arasında oluşturulan sepetlerin ve fiyat endekslerinin farkı bileşeni göz önüne alındığında, SAGP'de kısa dönemde sapmalar meydana gelmesi olasıdır. Dolayısıyla SAGP'nin yalnızca uzun dönemde geçerli bir kavram olması beklenmektedir (Krugman, Obstfeld ve Melitz, 1988; Wu, 1996: 59).

Ekonomi literatürünün tartışmalı ve ilgi çekici konularından biri olan SAGP, araştırmacılar ve politika yapıcılar tarafından yakından takip edilmektedir (He, Chou ve Chang, 2014: 37). Hem teoride hem de uygulamada büyük öneme sahip olan SAGP, belirli ülkeler ve ülke grupları için farklı ekonometrik test teknikleri kullanılarak test edilmektedir. SAGP kavramı birçok açıdan önem arz etmektedir (Chang ve Tzeng, 2011: 1383). Bunlardan birincisi, döviz kurunu tahmin etmek ve bir para biriminin aşırı veya düşük değerli olup olmadığını tespit etmek için SAGP bir kriter olarak kullanılmaktadır. İkincisi, birçok döviz kuru belirleme teorisinin temelinde SAGP bulunmaktadır. Üçüncüsü, SAGP hipotezinin geçerliliği iki ülkenin finansal anlamda entegre olup olmadığını göstermektedir (Holmes, 2001; Sarno, 2005). Son olarak, SAGP'nin geçerli olması durumunda döviz kurunun uzun dönem denge değerinde olduğu kabul edilmekte ve SAGP, uluslararası karşılaştırmalarda güvenilir bir gösterge olarak kullanılabilmektedir (Vasconcelos ve Junior, 2016: 115). Tüm bu faktörler dikkate alındığında SAGP hipotezinin geçerliliği çeşitli ülkeler ve ülke grupları için, farklı ampirik testler kullanılarak incelenmektedir.

SAGP’nin geçerliliği üç farklı ampirik test yöntemi kullanılarak araştırılmaktadır. Bunlardan birincisi korelasyon temelli yöntemler, ikincisi reel döviz kurlarının durağanlığının incelendiği birim kök test yöntemleri, üçüncüsü ise nispi fiyatlar ile döviz kurlarının uzun dönemde birlikte hareket edip etmediğinin sınandığı eş-bütünleşme test yöntemleridir (Froot ve Rogoff, 1995; Ma, Li ve Park, 2017: 211). Modern ekonometrik teknikler kullanılarak SAGP'nin geçerliliğinin sınandığı geniş bir literatür bulunmaktadır. İlk dönem çalışmalarda döviz kurunun durağan olmadığı sonucu ağırlık kazanmıştır. Bu durumun geleneksel birim kök testlerinin düşük gücünden ve verilerin kısa dönemli olmasından kaynaklandığı öne sürülmektedir (Cuddington ve Liang, 2000: 753). Diğer yandan uzun dönemli verilerin ve daha güçlü test tekniklerinin kullanıldığı son dönem çalışmalarda ise reel döviz kurunun durağanlığı doğrultusunda SAGP'nin geçerliliğini destekleyen kanıtlara ulaşılmaktadır (Brissimis, Sideris ve Voumvaki, 2005: 960). Modern bir birim kök testi 
olarak BCIPS testi, yatay kesit bağımlılı̆ını göz önünde bulundurması, çok faktörlü yapıyı dikkate alması ve Fourier özelliği ile yapısal değişimlerde yumuşak geçiş sürecine izin vermesi açısından geleneksel ve yapısal kırımayı dikkate almayan birim kök testlerine göre oldukça avantajlıdır. Sunduğu avantajlar sebebiyle N-11 ülkeleri için elde edilen birim kök analiz sonuçlarının daha güçlü olduğu ve bu doğrultuda daha tutarlı politika önerilerinde bulunulabileceği ifade edilebilir.

N-11 ülkeleri kavramı, ilk olarak 2005 yılında çok uluslu finansal danışmanlık ve yatırım bankası "Goldman ve Sachs" tarafından ileri sürülmüştür. N-11 ülkeleri BRIC (Brezilya, Rusya, Hindistan, Çin) benzeri küresel bir etkiye sahip olma potansiyeli taşıyan ülkelerden seçilmiştir (Sachs, 2007). Bu ülkelerin seçiminde barındırdıkları nüfusun yanı sıra yurt içi ve yabancı yatırımları, ekonomik ve politik istikrarları, kaliteli eğitim imkanları, ticari dışa açıklık ve ekonomik büyümeye dair umut vadeden görünümleri belirleyici olmuştur. Gelecek BRIC (Next BRIC) olarak da ifade edilen N-11 ülkelerinin aşması gereken birçok sorunu olmasına rağmen BRIC ülkeleri ile bu 11 ülkenin 21. yüzyılda dünyanın en büyük ekonomileri arasında yerini alma potansiyeline sahip olduğu ifade edilmektedir (Wilson, 2007: 2-8).

Bu çalışmanın amacı, dokuz (Mısır, Endonezya, İran, Güney Kore, Meksika, Nijerya, Pakistan, Filipinler ve Türkiye) N-11 (Next-eleven) ülkesinde 1970-2019 dönemi reel (efektif) döviz kuru verisini kullanarak, ilgili ülkeler için SAGP hipotezinin geçerliliğini sınamaktır. Bu amaçla çalışmada Lee vd. (2016) tarafından önerilen BCIPS (The breaks and cross-sectional dependence augmented Im, Pesaran ve Shin) panel birim kök testi kullanılmıştır. Çalışmanın özgün yönleri ve literatüre yapacağı katkılar şu şekilde sıralanabilir: illk olarak, makroekonomik göstergelerde şokların etkisinin kalıcı olup olmadığının tespit edilmesi uygun politikaların belirlenmesi ve etkinliği açısından önemlidir. Dolayısıyla ekonomik istikrar açısından önemli bir makroekonomik gösterge olan döviz kurunda dalgalanmaların uzun dönemde dengeye gelip gelmediğinin saptanması özellikle gelişmekte olan ülkelerin uygulayacağı politikalarda önem arz etmektedir. İkincisi, N-11 ülkelerinde SAGP'nin geçerli olup olmadığının tespitinde ikinci nesil ve güncel bir birim kök test tekniğinin kullanılmasıdır. Zira birinci nesil birim kök testleri yatay kesit bağımlılı̆ını göz ardı ederken, ikinci nesil birim kök testleri ise çoğunlukla yapısal değişimleri dikkate almamaktadır.

Çalışmanın geri kalan kısmı şu şekilde tasarlanmıştır. Çalışmanın ikinci bölümünde teorik çerçeveye, üçüncü bölümde literatür taramasına yer verilmektedir. Veri seti ve yöntemin anlatıldığı dördüncü bölümü, analiz sonuçlarının raporlandığı beşinci bölüm takip etmektedir. Ardından sonuç ve öneriler kısmı ile çalışma tamamlanmaktadır.

\section{Teorik Çerçeve}

Döviz kuru, ekonomik varlıklar için yurt içi ve dış dünya arasında önemli bir bağlantı aracıdır. Bu nedenle döviz kurlarının davranışı doğru ve ayrıntılı bir biçimde analiz edilmelidir. Uzun süreli ve ani döviz kuru sapmalarının ciddi makroekonomik dengesizlikler oluşturabileceği ifade edilmektedir. Örneğin, 1990'ı ve 2000 'li yıllardaki gelişmeler, döviz kuru uyumsuzluğunun maliyetinin çok yüksek olduğunu ortaya koymuştur. Bu bağlamda politika yapıcılar, bir ülkenin dış rekabet gücünü temsil etmek için ve dalgalı döviz kuru sisteminde döviz kurlarının gerçek değerini tespit edebilmek amacıyla SAGP teorisini kullanmışlardır (Berg, Borensztein, Milesi-Ferretti ve Pattillo, 1999; Qayyum, Khan, Khair-u-Zaman ve Saqib, 2004: 721). SAGP teorisi, döviz kuru ile nispi fiyat oranları arasında aşağıdaki ilişkiyi ifade etmektedir. Bu ilişki eşitlik (1)'de açıklanmaktadır (Narayan, 2005: 1064):

$$
R E R_{t}=N E R \frac{P_{t}^{*}}{P_{t}}
$$

Eşitlik (1)'de $R E R_{t}$, reel döviz kurunu, $N E R$ ise nominal döviz kurunu göstermektedir. $P_{t}^{*}$ ve $P_{t}$ sırasıyla yurt dışı ve yurt içi fiyat düzeylerini temsil etmektedir. SAGP teorisi, yurt içi fiyat düzeyi yabancı fiyat düzeyine göre arttığında veya azaldığında, yerli paranın orantılı olarak değer kaybettiği veya değer kazandığı yaklaşımını benimser. Bu sürecin temel dayanağı ise malların ve piyasaların entegre olduğu dolayısıyla ülkeler arasında bir fiyat farkı varsa bile fiyat seviyeleri eşitlenene kadar arbitraj mekanizmasının devrede olacağıdır. Logaritmik formda reel döviz kuru eşitlik (2)'de sunulmaktadır (Narayan, 2005: 1064): 
$\ln R E R_{t}=\ln N E R_{t}+\ln P_{t}^{*}-\ln P_{t}$

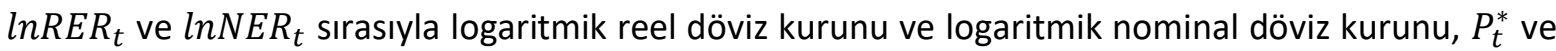
$\boldsymbol{P}_{\boldsymbol{t}}$ sırasıyla logaritmik yurt içi fiyat endeksini ve logaritmik yurt dışı fiyat endeksini göstermektedir. Eşitlik (2)'de reel döviz kuru, nominal döviz kuru ile yurt dışı fiyat endeksinin toplamından yurt içi fiyat endeksinin çıkarılması ile hesaplanmaktadır. Reel döviz kuru birinci dereceden otoregresif bir süreç izliyorsa, AR(1) modeli eşitlik (3)'teki gibi yazılmaktadır (Narayan, 2005: 1064):

$$
\ln R E R_{t}=\alpha_{0}+\alpha_{1} R E R_{t-1}+\varepsilon_{t}
$$

Eşitlik (3)'te $\varepsilon_{t}$, otokorelasyonsuz bir hata sürecini ve $\alpha_{0}$, sabit terimi temsil etmektedir. Uzun dönemde SAGP'nin geçerli olması için $\widehat{\alpha_{1}}<1$ koşulunun sağlanması gerekmektedir. Bu koşulun sağlanması, döviz kurunun durağan bir süreç izlediğini göstermektedir. Diğer yandan $\widehat{\alpha_{1}}=1$ olması koşulunda SAGP'nin geçerli olmadığı dolayısıyla reel döviz kurunun birim köklü olduğu ifade edilmektedir.

Satın alma gücü paritesi, reel döviz kurlarının durağan olduğu hipotezini desteklemektedir. Sıfır hipotezi reel döviz kurunun durağan olmadığı yani SAGP'ye göre ayarlamanın olmadığı varsayımına dayanırken, alternatif hipotez ise reel döviz kurunun durağan olduğu yani SAGP'ye göre ayarlamanın gerçekleştiği varsayımına dayanmaktadır. Sonuç itibarıyla sıfır hipotezinin reddedilmesi, reel döviz kurunun sabit bir ortalamaya döndüğünü ima eder ve bu nedenle uzun dönemde SAGP'nin geçerli olduğu kabul edilir (Taylor ve Taylor, 2004: 145-146).

\section{Literatür Taraması}

Satın alma gücü paritesinin geçerliliği araştırmacılar ve politika yapıcılar tarafından çok tartışılan ve başvurulan önemli konulardan biridir. Bu bağlamda literatürde SAGP'nin geçerli olup olmadığını incelemek amacıyla reel döviz kurunun analiz edildiği çok sayıda çalışma yer almaktadır. Bu nedenle anlatımı kolaylaştırmak adına literatür taramasında sınıflandırmaya gidilmiş ve ilk olarak SAGP hipotezinin çoğunlukla geçerli olmadığı çalışmalara yer verilmiştir. Ardından SAGP hipotezinin çoğunlukla geçerli olduğu çalışmalar yer almaktadır.

SAGP hipotezinin ağırlıklı olarak geçerli olmadığı sonucuna ulaşan çalışmalara örnek olarak şunlar verilebilir: Genberg (1978), 14 ülkede döviz kurları ile nispi fiyat seviyeleri arasındaki ilişkiyi sabit ve dalgalı döviz kurları dönemleri için incelemiştir. Çalışmada hem sapmaların ortalama büyüklüğünün hem de sürelerinin 1957-1966 sabit oranlı döviz kuru döneminde dalgalı döneme göre daha küçük olduğu ortaya konulmuştur. Edison ve Klovland (1987), Norveç ve Birleşik Krallık için SAGP hipotezini 1874-1971 ve 19141928 olmak üzere iki dönem halinde analiz etmişlerdir. Analiz sonuçlarında SAGP hipotezinin 1874-1971 dönemi için desteklenemez iken, 1914-1928 dönemi için ise desteklendiği yönünde bulgulara ulaşılmıştır. Abuaf ve Jorion (1990), etkin finansal ve emtia spekülasyonları koşullarında dahi reel döviz kurunun rassal bir yürüyüş izlemesi için herhangi bir teorik neden olmadığını ileri sürmüşlerdir. Çoğu döviz kuru modelinin temeli olan uzun dönemli SAGP için rassal yürüyüş hipotezi doğru ise bu varsayımda uygulanan ampirik testlerin belirleyici olduğuna vurgu yapılmıştır. O güne kadar, SAGP hipotezi için çoğu ampirik testin reel döviz kurunun rassal bir yürüyüş izlediği hipotezini reddetmeyi başaramadığı dile getirilmiştir. Ancak bu sonuçların kullanılan zayıf test tekniklerinden kaynaklandığı ifade edilmiştir. Corbae ve Ouliaris (1991), 1890-1984 dönemi için Avustralya için SAGP hipotezinin geçerliliğini test etmişlerdir. Analiz sonuçlarında Avusturya için SAGP hipotezinin geçerli olmadığında dair bulgulara ulaşılmıştır. MacDonald (1993), döviz kurları ile nispi fiyatlar arasındaki uzun dönemli ilişki yanı sıra döviz kurunun nispi fiyatlara göre orantılı hareket edip etmediğini tespit etmeyi amaçlamıştır. Çalışmada döviz kurunun nispi fiyatlarla orantılı hareket etmediği sonucuna ulaşılmıştır. Zhou (1997), çalışmasında yüksek enflasyonlu ülke konumundaki Brezilya, İsrail, Meksika ve Kongo Demokratik Cumhuriyeti'nde SAGP hipotezinin geçerliliğini incelemiştir. Bu ülkelerin döviz kurları ve tüketici fiyat endekslerinin zaman serisi davranışlarını tespit etmek için Zivot ve Andrews (1992)'in kırımalara izin veren birim kök testi kullanılmıştır. Birim kök sonuçlarına göre bu ülkelerde reel döviz kuru verisinin birinci dereceden entegre olduğunu ortaya konulmuştur. Doğanlar (1999), Hindistan, Endonezya, 
Pakistan, Filipinler ve Türkiye için SAGP hipotezinin geçerliliğini test etmiştir. Analiz sonuçlarında sadece Türkiye için SAGP hipotezinin geçerli olduğuna dair kanıtlar ortaya konulmuştur. Lothian ve Taylor (2000), Cuddington ve Liang (2000)'ın makalesini değerlendirmişlerdir. Çalışmada trend terimlerinin önemine vurgu yapılmış, trend terimlerinin reel döviz kurunun ortalamaya dönmesinde önemli bir faktör olduğu ifade edilmiştir. Holmes (2001), 30 az gelişmiş ülke örneği üzerinde SAGP hipotezinin geçerli olup olmadığını test etmiştir. Bu doğrultuda çalışmada Im, Pesaran ve Shin (1997) tarafından öne sürülen ve heterojen panel veri analizine uygun birim kök testi kullanılmıştır. 1973-1999 dönemini kapsayan ve üç aylık verilerin kullanıldığı çalışmada çoğu az geliş̧iş ülke için SAGP hipotezinin desteklenmediğine dair kanıtlara ulaşılmıştır. Payne, Lee ve Hofler (2005), Hırvatistan için SAGP'nin geçerliliğini 1992-1999 dönemi için incelemişlerdir. Çalışmada yapısal kırılmaya izin veren Lee ve Strazicich (2004) LM test yöntemi kullanılmıştır. Analiz sonuçlarında Hırvatistan için SAGP hipotezinin desteklenmediğini ortaya konulmuştur. Payne vd. (2005), 1992-1999 döneminde Hırvatistan için SAGP'nin geçerli olup olmadığını incelemişlerdir. Çalışmada Lee ve Strazicich (2004)'in yapısal kırılmaya izin veren LM birim kök testi kullanılmışır. Birim kök test sonuçlarında Hırvatistan ekonomisi için SAGP'nin geçerliliğini destekleyen kanıtlara ulaşılamamıştır. Yılancı (2012), Bulgaristan, Hırvatistan, Çek Cumhuriyeti, Macaristan, Litvanya, Makedonya, Polonya ve Romanya'da SAGP hipotezinin geçerliliğini Kapetanios, Shin ve Snell (2003)'in KSS ve rolling-KSS birim kök testleri ile araştırmıştır. KSS birim kök sonuçlarına göre sadece Romanya'da, rolling-KSS birim kök sonuçlarına göre ise sadece Polanya'da SAGP hipotezinin geçerli olduğu tespit edilmiştir. Ocal (2013), Romanya'da 1991-2012 yıllları arası SAGP hipotezinin geçerliliğini Zivot-Andrews birim kök testi ile yapısal kırılmayı hesaba katarak incelemiştir. Analiz sonuçlarına göre Romanya'da SAGP hipotezi geçerli değildir. Çalışmada ayrıca SAGP'nin sınanması sürecine dair önceki literatürün doğrusal birim kök testlerinde yoğunlaştığı ancak son dönem çalışmaların doğrusal olmayan ve yapısal kırılmaları dikkate alan birim kök testlerine yöneldiği ifade edilmiştir.

SAGP hipotezinin ağırlıklı olarak geçerli olduğu sonucunu içeren çalışmalara ise örnek olarak şunlar verilebilir: Gailliot (1970), SAGP hipotezinin uluslararası ticarette geçerliliğini ampirik olarak incelemiştir. Çalışmada SAGP hipotezinin uluslararası ticarette geçerliliğine dair güçlü kanıtlara ulaşıımıştır. MacDonald ve Taylor (1994), sterlin-dolar döviz kuru için parasal bir model kurmuştur. Bu modelde çok değişkenli bir eşbütünleşme tekniği kullanılarak, kısıtlamasız bir parasal modelin uzun dönem döviz kurunu analiz etmek için geçerli olduğu ortaya konulmuştur. Papell (1997), çalışmasında sanayileşmiş ülkelerde SAGP hipotezinin geçerli olup olmadığını araştırmıştır. Analiz sonuçlarında büyük ölçüde SAGP hipotezinin geçerli olduğuna dair bulgulara ulaşılmıştır. Culver ve Papell (1999), 20 Avrupa ülkesi için SAGP hipotezini Kwiatkowski, Phillips, Schmidt ve Shin (1992) tarafından geliştirilen birim kök testi ile analiz etmişlerdir. Analiz sonuçlarında çoğu Avrupa ülkesi için SAGP hipotezinin desteklendiğine dair kanıtlar bulunmuştur. Taylor ve Peel (2000), nominal döviz kurunun parasal temellerle tutarlı seviyeden sapmasının doğrusal olmama olasılığını araştırmışlardır. Bu araştırma için 1973-1996 dönemi için Birleşik Krallık, Almanya ve ABD’nin üçer aylık verileri ele alınmıştır. Analiz sonuçlarında nominal değerin sapmalarını tanımlayan seride anlamlı doğrusal olmayan kanıtlara ulaşılmıştır. Duncan ve Calderon (2003), Şili gibi yükselen bir piyasa ekonomisinde SAGP koşulunun geçerliliğini araştırmışlardır. Bu doğrultuda 1810-2002 yılları için Díaz, Lüders ve Wagner (2003) tarafından oluşturulan döviz kuru verileri kullanıımıştır. Analiz sonuçları Şili için SAGP'nin geçerli olduğuna dair kanıtlar sunmuştur. Nusair (2003), Asya mali krizinden etkilenen Endonezya, Güney Kore, Malezya, Singapur, Filipinler ve Tayland ülkelerinde 1973-1999 dönemi için SAGP hipotezinin geçerliliğini araştırmıştır. Çalışmada Dickey ve Fuller (ADF), Phillips ve Perron (PP) ve Kwiatkowski Kwiatkowski, Phillips, Schmidt, and Shin (KPSS) tarafında ileri sürülen birim kök testleri kullanılmıştır. ADF ve PP birim kök test sonuçları Endonezya, Güney Kore ve Tayland için reel döviz kurunun durağanlığına dair kanıtlar ortaya koymuştur. Bu bağlamda Endonezya için güçlü kanıtlar söz konusu iken, Güney Kore ve Tayland için zayıf kanıtlara ulaşılmıştır. Diğer yandan KPSS birim kök sonuçları ise Endonezya, Güney Kore, Malezya ve Tayland için SAGP'nin geçerli olduğuna dair daha güçlü kanıtlar sunmuştur. Alba ve Papell (2007), gelişmiş ve gelişmekte olan 84 ülkenin reel döviz kuru verisinin durağanlığını panel birim kök testleri ile çok boyutlu bir şekilde araştırmışlardır. Çalışmada 84 ülkenin tümü için tek bir panel üzerinden analiz sonuçları elde etmenin doğru bir yaklaşım olmadığından bahsedilmiştir. Bu bağlamda 84 ülke Afrika, Latin Amerika, Avrupa, Asya ülkeleri şeklinde alt panellere ayrılmıştır. Ayrıca bu 84 ülke ticari açıklık, uzaklık, ekonomik büyüme, enflasyon ve nominal döviz kurundaki oynaklık ölçütlerine göre alt panellere ayrılmış ve bu alt paneller üzerinden analizler 
gerçekleştirilmiştir. SAGP'nin Avrupa ve Latin Amerika ülkeleri için geçerli olduğu ancak Afrika ve Asya ülkeleri için geçerli olmadığı sonucuna ulaşılmıştır. Bununla birlikte ticari açıklığı yüksek olan, Amerika Birleşik Devletleri'ne daha yakın ve daha düşük enflasyona sahip ülkeler için SAGP'nin geçerliliğine dair daha güçlü kanıtlara ulaşılmıştır. Chowdhury (2007), SAGP hipotezinin geçerliliğini, Bangladeş ve dört ticaret ortağı ABD, Euro bölgesi, Japonya ve Hindistan için 1994-2002 dönemi reel döviz kuru verileri kullanarak araştırmıştır. Çalışmada doğrusal olmayan ekonometrik teknikler kullanılmıştır. Çalışma bulguları, reel döviz kurlarında doğrusal olmayan uyarlamayı öngören teorik modellerin geçerliliğini desteklemektedir. Ayrıca bulgular SAGP'nin geçerliliği için güçlü kanıtlar ortaya koymuştur. Kalyoncu ve Kalyoncu (2008), 25 OECD ülkesinde 1980-2005 için SAGP'nin geçerliliğini panel birim kök ve her bir ülke için ADF birim kök testi kullanarak incelemişlerdir. ADF birim kök sonuçlarına göre reel döviz kurunun birim köklü olduğu, panel birim kök sonuçlarına göre ise reel döviz kurunun durağan bir yapıya sahip olduğu tespit edilmiştir. ADF birim kök sonuçlarının, OECD ülkelerinde SAGP'yi desteklemediği ancak panel birim kök test sonuçlarının SAGP'yi desteklediği görülmüştür. Abumustafa ve Feridun (2010), Mısır, Ürdün ve Türkiye'de SAGP'nin geçerliliğini $A D F$, PP ve KPSS testleri aracılığıyla test etmişlerdir. ADF ve PP test sonuçlarına göre bu üç ülkede SAGP hipotezi geçerli değil iken, KPSS test sonuçlarına göre SAGP hipotezinin geçerli olduğu belirlenmiştir. Çalışmada SAGP'nin geçerliliğinde seçilen ülkelerden ziyade kullanılan test tekniğinin belirleyici olduğu vurgulanmıştır. Aslan, Kula ve Kalyoncu (2010), Türkiye için resmi ve karaborsa döviz kurları üzerinde SAGP hipotezinin geçerliliğini araştırmışlardır. Çalışmada ADF ve PP gibi geleneksel birim kök testleri yanı sıra kırılmalara izin veren Zivot-Andrews birim kök testi kullanılmıştır. Geleneksel birim kök testlerinden SAGP'nin geçerliliğine dair güçlü kanıtlara ulaşılamamıştır. Yapısal kırılmaya izin veren Zivot-Andrews test sonuçlarından hem resmi hem de kara borsa döviz kurları için SAGP'nin geçerli olduğuna dair güçlü kanıtlar tespit edilmiştir. Chang, Su, Zhu ve Liu (2011), yedi Orta ve Doğu Avrupa ülkesi (Bulgaristan, Çek Cumhuriyeti, Macaristan, Polonya, Romanya, Rusya ve Slovakya) için reel döviz kurunun durağanlığını Breuer, McNown ve Wallace (2001)'ın doğrusal olmayan panel birim kök testi ile analiz etmişlerdir. Çalışmada Bulgaristan, Macaristan, Polonya, Romanya ve Rusya olmak üzere beşülke için SAGP'nin geçerli olduğuna dair güçlü kanıtlara ulaşılmıştır. Vasconcelos ve Junior (2016), Arjantin, Brezilya, Şili, Kolombiya, Meksika, Peru ve Venezuela için doğrusal ve doğrusal olmayan modeller üzerinden birim kök testleri yardımı ile SAGP'nin geçerliliğini sınamışlardır. Bu doğrultuda çalışmada Harvey, Leybourne ve Xiao (2008)'nun doğrusallık testi, Lee ve Strazicich (2003)'in doğrusal ve kırılmalı birim kök testi ve Kruse (2011)'nin doğrusal olmayan birim kök testi kullanıımıştır. Sonuçlar, reel efektif döviz kuru verisinin Arjantin, Brezilya, Şili, Kolombiya ve Peru'da doğrusal karakteristikli olduğunu, Meksika ve Venezuela'da ise doğrusal olmayan karaktere sahip olduğunu ortaya koymuştur. Buna göre doğrusal birim kök testlerinden Şili ve Peru için reel efektif döviz kurunun durağan olduğu, doğrusal olmayan birim kök testlerinden ise Meksika için reel efektif döviz kurunun durağan olduğu tespit edilmiştir. Yıldııı (2017), Türkiye ile dört büyük ticaret ortağı olan Avrupa Birliği, Rusya, Çin ve $A B D$ arasında SAGP hipotezinin geçerliliğini incelemiştir. Çalışmada geleneksel doğrusal birim kök testleri yanı sıra doğrusal olmayan birim kök testleri kullanılmıştır. Doğrusal olmayan birim kök analizlerinden elde edilen bulgular, SAGP'nin geçerliliğine dair görece daha güçlü kanıtlar ortaya koymuştur. Ayrıca çalışmada serbest ticaret anlaşması olan ülkelerin reel döviz kurlarının doğrusal durağanlığına dair daha fazla bulguya ulaşılmıştır. Altıner ve Bozkurt (2018), 1994-2017 yılları arasında gelişmekte olan 7 ülke (E-7) için SAGP hipotezini test etmişlerdir. Çalışmada SURADF ve yapısal kırılmaları dikkate alan PANKPSS birim kök testleri kullanılmıştır. PANKPSS birim kök sonuçlarına göre tüm ülkeler için SAGP hipotezinin geçerli olduğu tespit edilmiştir. Doğanlar, Mike ve Kızılkaya (2020), 1993-2018 dönemi 10 gelişmiş, 20 gelişmekte volan ve 15 piyasa ekonomisi olmak üzere 45 ülke için SAGP hipotezinin geçerliliğini incelemişlerdir. Çalışmada geleneksel birim kök testleri ile Fourier özellikli birim kök testleri kullanılmıştır. Fourier birim kök testi sonuçları SAGP'nin geçerliliği üzerine daha fazla kanıtlar sunmuştur. Bu doğrultuda 8 gelişmiş, 11 gelişmekte olan ve 7 piyasa ekonomisinde SAGP hipotezinin geçerli olduğunu belirlenmiştir. Xie, Chen ve Hsieh (2021), 23 OECD ülkesi ve Euro bölgesi ülkelerinin 1994-2019 dönemi için SAGP'nin geçerliliğini sınamışlardır. Çalışmanın dikkat çekici yönü, satın alma gücü paritesi hipotezinin geçerliliğinin dört farklı gösterge (PPP, TPPP, QPPP ve TQPPP) kullanılarak kırılmasız, kırılmalı ve fourier özelliklere sahip çeşitli birim kök analizleri ile kapsamlı bir şekilde araştırılmasıdır. Yeni geliştirilmiş bir dizi birim kök testi kullanılarak SAGP hipotezinin farklı versiyonlarının test edildiği çalışmada trend içeren SAGP (TPPP) hipotezinin geçerliliği yönünde daha güçlü kanıtlara 
ulaşılmıştır. Çalışmada ayrıca yapısal kırılmayı ve doğrusal olmama durumunu birlikte dikkate alan yöntemlerin kullanılarak SAGP hipotezinin sağlamlı̆ının kontrol edilmesi gerektiği vurgulanmıştır.

Literatürde görüleceği üzere geleneksel birim kök testlerinin kullanıldığı çalışmalarda SAGP hipotezini destekleyen daha az kanıtlara ulaşılmıştır. Yapısal kırılmalara ve yatay kesit bağımlıı̆ına izin veren, doğrusal olmamayı göz önünde bulunduran test yöntemlerinin kullanılması ile sonuçlarda SAGP hipotezinin geçerli olduğuna dair daha fazla kanıtlar ortaya konulmuştur.

\section{Veri Seti ve Yöntem}

Makroekonomik değişkenlerin istikrarı ve bu değişkenler üzerinde şokların etkisinin geçici olup olmadığı araştırmacılar ve politik karar alıılar için önemli bir inceleme alanıdır. Makroekonomik değişkenlerin uzun dönem dengesine ulaşıp ulaşmadıklarının bilinmesi, mevcut ve uygulanacak politikalar açısından belirleyicidir. Önemli bir makroekonomik gösterge olarak döviz kuru üzerinde şokların uzun dönemde nasıl bir etkiye sahip olduğunun tespit edilmesi ve buna uygun politika uygulamalarının hayata geçirilmesi ülkelerin iç ve dış ekonomik istikrarında kilit rol oynamaktadır. Bu doğrultuda bu çalışmada SAGP'nin geçerliliğinin Mısır, Endonezya, İran, Güney Kore, Meksika, Nijerya, Pakistan, Filipinler ve Türkiye için (N-9) 1970-2019 dönemi yıllık reel efektif döviz kuru verisi kullanılarak sınanması amaçlanmıştır. N-11 ülkeleri Bangladeş, Mısır, Endonezya, İran, Güney Kore, Meksika, Nijerya, Pakistan, Filipinler, Türkiye ve Vietnam ülkelerini kapsamaktadır. Illgili dönem itibarıyla Bangladeş ve Vietnam'a dair reel efektif döviz kuru verilerine ulaşılamadığından bu iki ülke çalışmaya dahil edilmemiştir.

Çalışmanın asıl değişkeni olan reel efektif döviz kuru (Reer) verisine Darvas (2012)'ın 178 ülke için ortaya koyduğu reel efektif döviz kuru çalışması temelinde "bruegel.org" adlı resmi internet sitesinden ${ }^{1}$ ulaşılmıştır. Çalışmada ortak faktör değişkenleri olarak yer alan ekonomik büyüme (Pergdp), tüketici fiyat endeksi (Inf) ve ticari dışa açıklık (Trade) değişkenlerine dair veriler ise Dünya Bankası'nın (WB) "Dünya Kalkınma Göstergeleri (WDI)" veri tabanından elde edilmiştir. Reer, Pergdp, Trade değişkenleri farklı birim ve ölçeklerde olduğundan logaritmik dönüşümleri hesaplanarak analizlerde kullanılmıştır. Eickmeier (2009) makroekonomik değişkenlerin analizinde 2 ve 6 arasında değişen ortak faktör kullanımının uygun olduğunu ifade etmektedir. Örneğin, Lee vd. (2016) çalışmasında 4 ortak faktöre, Zeren ve İşlek (2019) ise 3 ortak faktöre yer vermiştir. Bu bağlamda bu çalışmada ise 3 ortak faktöre (Pergdp, Inf, Trade) yer verilerek $m_{\max }=4$ üzerinden durağanlık analizleri gerçekleştirilmektedir.

Çalışmada yatay kesit bağımlıı̆ğının varlığı Breusch ve Pagan (1980) LM, Pesaran (2004) $C D_{\text {Im }}$ ve Pesaran, Ulah ve Yamagata (2008) LMadj testleri ile sınanmaktadır. Breusch ve Pagan (1980), görece büyük bir T ve nispeten küçük bir $\mathrm{N}$ durumunda etkin olan, Lagrange Çarpanına (LM) dayalı bir yatay kesit bağımlılığı testi ileri sürmüştür. LM test istatistiği eşitlik (4)'te gösterilmektedir (Breusch ve Pagan, 1980: 240-247):

$$
L M=T \sum_{i=1}^{N-1} \sum_{j=i+1}^{N} \hat{p}_{i j}^{2}
$$

LM testi, $T \rightarrow \infty$ ve $N \rightarrow \infty$ olması durumunda etkinliğini kaybetmektedir. Pesaran (2004), büyük panellerde etkinliğini kaybeden $\mathrm{LM}$ testinin ölçekli versiyonunu geliştirerek $\mathrm{CD}_{\operatorname{lm}}$ test istatistiğini ileri sürmüştür. Eşitlik (5)'te $\mathrm{CD}_{\mathrm{Im}}$ test istatistiği sunulmaktadır:

$$
C D_{l m}=\left(\frac{1}{N(N-1)}\right)^{\frac{1}{2}} \sum_{i=1}^{N-1} \sum_{j=i+1}^{N}\left(T \hat{p}_{i j}^{2}-1\right)
$$

Pesaran vd. (2008), T>N ve N>T olduğu her iki durumda da gücünü kaybetmeyen, sapmalara karşı duyarlı bir LM test istatistiği geliştirmiştir. LMadj test istatistiğine eşitlik (6)'da yer verilmektedir:

$$
L M_{a d j}=\sqrt{\left(\frac{2}{N(N-1)}\right)} \sum_{i=1}^{N-1} \sum_{j=i+1}^{N} \hat{p}_{i j} \frac{(T-k) \hat{p}_{i j}^{2}-\mu_{T_{\mathrm{i} J}}}{\sqrt{v_{T_{\mathrm{I} J}}^{2}}}
$$


Lee vd. (2016), Pesaran, Smith ve Yamagata (2013)'nın çok faktörlü hata yapısı modelini geliştirerek, yatay kesit bağımlılığını göz önünde bulunduran, deterministik bileşendeki gözlenemeyen faktörü dikkate alan ve Fourier fonksiyonu ile yumuşak kırılmaya izin veren yeni bir test ileri sürmüştür. Bu test kırılmalarla genişletilmiş IPS (BCIPS) panel birim kök testi olarak adlandırımaktadır. BCIPS panel birim kök testinin T>50 olması koşulunda iyi bir performans sergilediği, $T>100$ olması koşulunda ise oldukça güçlü sonuçlar ortaya koyduğu ileri sürülmektedir.

Lee vd. (2016) tarafından öne sürülen BCIPS test istatistiği sürecinde "yatay kesitlerle güçlendirilmiş ADF" testi (CADF), Fourier fonksiyonu ile genişletilmiş ve "kırılmalı ve yatay kesit genişletilmiş" test istatistiği (BCADF) elde edilmiştir. BCADF test istatistiği süreci şu şekildedir:

Eşitlik (7)'de ortak faktörsüz (tek faktörlü), yatay kesit bağımlılığını ve kırılmaları göz önüne alan ADF denklemi gösterilmektedir.

$$
\Delta y_{i t}=c_{i, 0}+c_{i, 1} \sin \left(\frac{2 \pi k t}{T}\right)+c_{i, 2} \cos \left(\frac{2 \pi k t}{T}\right)+c_{i, 3} \bar{y}_{t-1}+c_{i, 4} \Delta \bar{y}_{t}+b_{i} y_{i, t-1}+e_{i, t}
$$

Çok faktörlü hata yapısının varlığı altında, kırılmalara ve yatay kesit bağımlıı̆ına izin veren ADF denklemi eşitlik (8)'de sunulmaktadır:

$$
\begin{gathered}
\Delta y_{i t}=c_{i, 0}+c_{i, 1} \sin \left(\frac{2 \pi k t}{T}\right)+c_{i, 2} \cos \left(\frac{2 \pi k t}{T}\right)+c^{\prime}{ }_{i, 3} \bar{z}_{t-1}+c^{\prime}{ }_{i, 4} \Delta \bar{z}_{t}+c^{\prime}{ }_{i, 5} \Delta \bar{z}_{t-1} \\
+c_{i, 6} \Delta y_{i, t-1}+b_{i} y_{i, t-1}+e_{i, t}
\end{gathered}
$$

Eşitlik (9)'da oluşturulan BCADF regresyonunda, $p$ ve $k$ sırasıyla optimal gecikme uzunluğunu ve frekans sayısını temsil etmektedir:

$$
\begin{aligned}
& \Delta y_{i t}=c_{i, 0}+c_{i, 1} \sin \left(\frac{2 \pi k t}{T}\right)+c_{i, 2} \cos \left(\frac{2 \pi k t}{T}\right)+c^{\prime}{ }_{i, 3} \bar{z}_{t-1}+c^{\prime}{ }_{i, 4} \Delta \bar{z}_{t}+\sum_{j=1}^{p} c^{\prime}{ }_{i, 5, j} \Delta \bar{z}_{t-j}+ \\
& \sum_{j=1}^{p} c^{\prime}{ }_{i, 5, j} \Delta \bar{z}_{t-j}+\sum_{j=1}^{p} c_{i, 6, j} \Delta y_{i, t-j}+b_{i} y_{i, t-1}+e_{i, t} t=1,2, \ldots, T
\end{aligned}
$$

BCADF istatistiklerinin ortalaması alınarak yapısal kırılmalara ve yatay kesit bağımlılığına izin veren BCIPS test istatistiğine ulaşılmaktadır. Fourier fonksiyonu ile kırılmaların yumuşak geçişine izin veren, kesitlerle güçlendirilmiş BCIPS test istatistiği eşitlik (10)'da görülmektedir:

$$
\operatorname{BCIPS}(N, T)=\frac{1}{N} \sum_{i=1}^{N} t_{i}(N, T)
$$

Eşitlik 10 'da yer alan $\mathbf{t}_{\mathbf{i}}(\mathbf{N}, \mathbf{T})$, bezdirici katsayılardan (nuisance parameters) arındırılmış, aynı sıralı $((\mathrm{N}, \mathrm{T})$ seq $\rightarrow \infty)$ ve eklemli $((\mathrm{N}, \mathrm{T}) \mathrm{j} \rightarrow \infty)$ sınırlayıcı dağılıma sahip bir istatistiği temsil etmektedir (Lee vd., 2016: 371).

\section{Analiz Sonuçları}

Panel birim kök analizlerinden önce örneklemi oluşturan ülkeler arasında kesitsel bağımlılığın var olup olmadığının kontrol edilmesi oldukça önemlidir. Aksi takdirde yatay kesit bağımlılığı test edilmeden elde edilen analiz sonuçları sapmalı ve tutarsız olmaktadır. Eğer kesitler arası bağımsızlık söz konusu ise birinci nesil panel birim kök testlerinden faydalanılabilir. Ancak kesitler arası bağımlılığın tespitinde ise yatay kesit bağımlılı̆ını dikkate alan ikinci nesil panel birim kök testleri kullanılmalıdır (Menyah, Nazlıoğlu ve WoldeRufael, 2004: 389). Çalışmada ilk aşamada yatay kesit bağımlılı̆̆ının varlığı Breusch ve Pagan (1980) LM, Pesaran (2004) CD Im ve Pesaran vd. (2008) LMadj testleri ile kontrol edilmektedir. Bu bağlamda Tablo 1'de yatay kesit bağımlılığı test sonuçları gösterilmektedir. Buna göre üç $C D$ testinde yatay kesit bağımlıı̆̆ının yokluğunu ifade eden sıfır hipotezi \%1 anlamlılık düzeyinde reddedilmiştir. Böylece dokuz N-11 ülkesinde tüm değişkenler için yatay kesit bağımlılı̆ının var olduğu tespit edilmiştir. Dolayısıyla çalışmaya yatay kesit 
bağımlılığı yanı sıra gözlenemeyen ortak faktör yapısını gözeten ve yumuşak kırılmaya izin veren yeni ve daha güçlü bir ikinci nesil test yöntemi ile devam edilmiştir.

Tablo 1. Yatay Kesit Bağımlılığı Test Sonuçları

\begin{tabular}{lccc}
\hline Değişkenler / CD Testleri & LM Testi & CD Im Testi & LMadj Testi \\
\hline Reer (Asıl Değişken) & $94,228^{* * *}(0,000)$ & $6,862^{* * *}(0,000)$ & $15,149^{* * *}(0,000)$ \\
Pergdp (Faktör Değişkeni) & $78,284^{* * *}(0,000)$ & $4,983^{* * *}(0,000)$ & $18,87^{* * *}(0,000)$ \\
Inf (Faktör Değişkeni) & $136,858^{* * *}(0,000)$ & $11,886^{* * *}(0,000)$ & $13,919^{* * *}(0,000)$ \\
Trade (Faktör Değişkeni) & $59,283^{* * *}(0,009)$ & $2,744^{* * *}(0,003)$ & $11,269^{* * *}(0,000)$ \\
\hline
\end{tabular}

Not: ***, \%1 anlamlıık düzeyini temsil etmektedir. Maksimum gecikme uzunluğu 3'tür. Parantez içindeki değerler olasılık değerlerini göstermektedir.

Pesaran vd. (2013), Pesaran (2007)'ın CADF (CIPS) testine ortak faktör yapısını dahil ederek gözlenemeyen ortak faktörleri dikkate alan bir panel birim kök testi geliştirmiştir. Lee vd. (2016) ise Pesaran vd. (2013)'nin ortak faktörlü panel birim kök testine fourier fonksiyonunu ekleyerek yapısal değişimleri dikkate alan yeni bir panel birim kök testi (BCIPS) önermiştir. Bu yeni panel birim kök testi yatay kesit bağımlılığını, gözlenemeyen ortak faktör yapısını ve yumuşak kırılmayı birlikte göz önüne almakta ve sahip olduğu bu özellikleri ile daha güçlü ve güvenilir sonuçlar sunmaktadır. Tablo 2 'de reel efektif döviz kuru için CIPS ve BCIPS test sonuçları gösterilmektedir. Tablo 2'de herhangi bir ortak faktörün dahil edilmediği tek

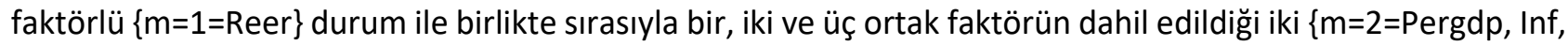
Trade $\}$, üç $\{m=3=($ Pergdp, Inf), (Pergdp, Trade), (Inf, Trade) $\}$ ve dört faktörlü $\{m=4=($ Pergdp, Inf, Trade) $\}$ farklı durumlara ait CIPS ve BCIPS sonuçlarına ulaşılmaktadır.

Tablo 2. Reel Efektif Döviz Kuru İ̧̧in CIPS ve BCIPS Sonuçları

\begin{tabular}{|c|c|c|c|c|}
\hline Reer & $(p, k)$ & {$[N, T]$} & CIPS & BCIPS \\
\hline$m=1$ & $(1,1)$ & {$[9,60]$} & $-3,014$ & $-3,781 * * *$ \\
\hline \multicolumn{5}{|l|}{$m=2$} \\
\hline Pergdp & $(1,4)$ & {$[9,60]$} & $-3,287^{* * *}$ & $-3,713 * * *$ \\
\hline $\operatorname{lnf}$ & $(1,5)$ & {$[9,60]$} & $-3,093 * * *$ & $-3,118 * * *$ \\
\hline trade & $(1,1)$ & {$[9,60]$} & $-2,914$ & $-3,977 * * *$ \\
\hline \multicolumn{5}{|l|}{$m=3$} \\
\hline Pergdp, Inf & $(1,4)$ & {$[9,60]$} & $-3,292 * * *$ & $-3,841 * * *$ \\
\hline Pergdp, Trade & $(1,1)$ & {$[9,60]$} & $-3,453 * * *$ & $-4,044 * * *$ \\
\hline Inf, Trade & $(1,1)$ & {$[9,60]$} & $-3,095$ & $-4,263 * * *$ \\
\hline \multicolumn{5}{|l|}{$m=4$} \\
\hline Pergdp, Inf, Trade & $(2,5)$ & {$[9,60]$} & $-3,644 * * *$ & $-2,736$ \\
\hline
\end{tabular}

Tablo 2'de CIPS testi sonuçlarına göre reel efektif döviz kurunun birim köke sahip olduğunu varsayan sıfır hipotezi 8 farklı durumun 5'inde reddedilmiştir. BCIPS test sonuçlarına göre ise 8 farklı durumdan sadece bir durum dışında geri kalan tüm farklı durumlar için birim kökün varlığını öne süren sıfır hipotezi reddedilmiştir. Yapısal değişimlerde yumuşak geçişe izin veren BCIPS test sonuçlarında nispeten daha fazla farklı durum için durağanlığa dair kanıtlara ulaşılımıştır. Sonuç itibarıyla toplam 16 farklı durumdan 12'sinde birim kökün varlığı reddedilerek N-11 ülkelerinde reel efektif döviz kurunun durağan olduğu belirlenmiştir. 


\section{Sonuç ve Öneriler}

Ekonomik istikrar kavramı makroekonomik değişkenlerde öngörülebilir ve makul ölçülerde bir dalgalanmayı ifade etmektedir. Bu bağlamda temel makroekonomik değişkenlerin istikrarı ve şokların bu değişkenler üzerindeki etkisinin kalıcı olup olmadığının belirlenmesi araştırmacılar ve karar alıcılar açısından önem arz etmektedir. Temel makro ekonomik bir gösterge olan döviz kuru üzerinde şokların kalıcı olması, şokların etkisinin devam ettiğini, diğer bir ifadeyle reel döviz kuru üzerindeki dalgalanmaların uzun dönem ortalamasına gelemediğini, geçici olması ise şokların etkisinin ortadan kalktığını, yani reel döviz kuru üzerindeki dalgalanmaların uzun dönem dengesine ulaştığını ifade etmektedir.

Bu çalışmanın amacı N-11 ülkeleri için 1970-2019 döneminde SAGP hipotezinin geçerli olup olmadığını tahmin etmektir. Bu amaçla yapılan ampirik analiz sonucunda N-11 ülkelerinde SAGP hipotezinin geçerli olduğu belirlenmiştir. Analiz sonuçları, uygulanan test yöntemi ve SAGP hipotezinin geçerli olması bakımından Chang vd. (2011), Yıldııım (2017), Doğanlar vd. (2020) ve Xie vd. (2021) çalışmaları ile benzerlik göstermektedir. Buna göre N-11 ülkelerinde reel (efektif) döviz kurunun sabit olduğu, şokların kurlar üzerinde kalıcı bir etki oluşturmadığını, sapmanın uzun dönem ortalamasına döneceği söylenebilir. Diğer bir ifade ile $\mathrm{N}$-11 ülkelerinde nominal döviz kurlarının fiyat farklılıklarını ortadan kaldıracak şekilde hareket ettiği, dolayısıyla istikrarlı bir döviz kuru politikasının geçerli olduğu ortaya konmuştur. Tüm bu sonuçlardan hareketle, N-11 ülkelerinde politika yapıcılar için SAGP'nin, milli gelir ve refah karşılaştırmalarında, döviz kuru politikalarının ve dış ticaret stratejilerinin belirlenmesinde sağlıklı ve güvenilir göstergelerden biri olarak kullanılabileceği söylenebilir. Gelecekte yapılacak çalışmalarda yapısal kırılmayı, doğrusal olmama durumunu ve heterojeniteyi dikkate alan daha güçlü tahmin yöntemleri kullanılarak SAGP hipotezinin geçerliliği her bir $\mathrm{N}-11$ ülkesi ve farklı ülke grupları için sınanabilir.

\section{Beyan ve Açıklamalar (Declarations and Disclosures)}

Yazarların Etik Sorumlulukları (Ethical Responsibilities of Authors): Bu çalışmanın yazarı, araştırma ve yayın etiği ilkelerine uyduğunu kabul etmektedir.

Çıkar Çatışması (Conflicts of Interest): Yazar tarafından herhangi bir çıkar çatışması beyan edilmemiştir.

Finansal Destek (Funding): Yazar, çalışmanın hazırlanması ve/veya yayınlanması sürecinde herhangi bir finansal destek almamışır.

Yazar Katkı Oranı (Author Contributions): Yazar; kavramlaştırma ve çalışma dizaynı, verilerin toplanması, verilerin analizi ve sonuçların yorumlanması, çalışmanın ilk/taslak halinin yazılması, çalışmanın gözden geçirilmesi ve düzenlenmesi/düzeltilmesi aşamalarından tek başına sorumlu olduğunu beyan etmektedir.

intihal Denetimi (Plagiarism Checking): Bu çalışma, intihal tarama programı kullanılarak intihal taramasından geçirilmiştir.

\section{Son Notlar}

1. www.bruegel.org

\section{Kaynaklar}

Abuaf, N., \& Jorion, P. (1990). Purchasing power parity in the long run. The Journal of Finance, 45(1), 157-174.

Abumustafa, N. I., \& Feridun, M. (2010). Explaining the long-term real equilibrium Exchange rates through purchasing power parity (PPP): An empirical investigation on Egypt, Jordan and Turkey. African Journal of Business Management, 4(7), 1260-1265.

Alba, J. D., \& Papell, D. H. (2007). Purchasing power parity and country characteristics: Evidence from panel data tests. Journal of Development Economics, 83(1), 240-251.

Altıner, A., \& Bozkurt, E. (2018). The validity of purchasing power parity hypothesis in E-7 countries: Panel data analysis. Business and Economics Research Journal, 9(4), 735-747. 
Arize, A. C., Malindretos, J., \& Ghosh, D. (2015). Purchasing power parity-symmetry and proportionality: Evidence from 116 countries. International Review of Economics \& Finance, 37, 69-85.

Aslan, A., Kula, F., \& Kalyoncu, H. (2010). Additional evidence of long-run purchasing power parity with black and official exchange rates. Applied Economics Letters, 17(14), 1379-1382.

Balassa, B. (1964). The purchasing-power parity doctrine: A reappraisal. Journal of Political Economy, 72(6), 584-596.

Baum, C. F., Barkoulas, J. T., \& Caglayan, M. (2001). Nonlinear adjustment to purchasing power parity in the post-Bretton Woods era. Journal of International Money and Finance, 20(3), 379-399.

Berg, A., Borensztein, E., Milesi-Ferretti, G. M., \& Pattillo, C. (1999). Anticipating balance-of-payments crises. Washington DC: International Monetary Fund, 1-34.

Breuer, J. B., McNown, R., \& Wallace, M. S. (2001). Misleading inferences from panel unit-root tests with an illustration from purchasing power parity. Review of International Economics, 9(3), 482-493.

Breusch, T. S., \& Pagan, A. R. (1980). The Lagrange multiplier test and its applications to model specification in econometrics. The Review of Economic Studies, 47(1), 239-253.

Brissimis, S. N., Sideris, D. A., \& Voumvaki, F. K. (2005). Testing long-run purchasing power parity under exchange rate targeting. Journal of International Money and Finance, 24(6), 959-981.

Carvalho, M., \& Júlio, P. (2012). Digging out the PPP hypothesis: An integrated empirical coverage. Empirical Economics, 42(3), 713-744.

Chang, H. L., Su, C. W., Zhu, M. N., \& Liu, P. (2011). Re-examining long-run purchasing power parity for Central and Eastern European countries: Nonlinear panel unit root tests. Applied Economics Letters, 18(5), 411-415.

Chang, T., Lee, C. H., \& Liu, W. C. (2012). Nonlinear adjustment to purchasing power parity for ASEAN countries. Japan and the World Economy, 24(4), 325-331.

Chang, T., \& Tzeng, H. W. (2011). Long-run purchasing power parity with asymmetric adjustment: Further evidence from nine transition countries. Economic Modelling, 28(3), 1383-1391.

Chowdhury, I. (2007). Purchasing power parity and the real exchange rate in Bangladesh: A nonlinear analysis. Journal of the Asia Pacific Economy, 12(1), 61-75.

Corbae, D., \& Ouliaris, S. (1988). Cointegration and tests of purchasing power parity. The Review of Economics and Statistics, 70(3), 508-511.

Corbae, D., \& Ouliaris, S. (1991). A test of long-run purchasing power parity allowing for structural breaks. Economic Record, 67(1), 26-33.

Cuddington, J. T., \& Liang, H. (2000). Purchasing power parity over two centuries? Journal of International Money and Finance, 19(5), 753-757.

Culver, S. E., \& Papell, D. H. (1999). Long-run purchasing power parity with short-run data: Evidence with a null hypothesis of stationarity. Journal of International Money and Finance, 18(5), 751-768.

Darvas, Z. (2012). Real effective exchange rates for 178 countries: A new database, 1-35.

Díaz, J., Lüders, R., \& Wagner, G. (2003). La República en Cifras: Chile 1810-2000. Manuscript, Central Bank of Chile.

Dickey, D. A., \& Fuller, W. A. (1979). Distribution of the estimators for autoregressive time series with a unit root. Journal of the American Statistical Association, 74(366a), 427-431.

Doganlar, M. (1999). Testing long-run validity of purchasing power parity for Asian countries. Applied Economics Letters, $6(3), 147-151$.

Doğanlar, M., Mike, F., \& Kızılkaya, O. (2020). Testing the validity of purchasing power parity in alternative markets: Evidence from the fourier quantile unit root test. Borsa Istanbul Review, 1-9.

Dornbusch, R. (1976). Expectations and exchange rate dynamics. Journal of Political Economy, 84(6), 1161-1176.

Duncan, R., \& Calderón, C. (2003). Purchasing power parity in an emerging market economy: A long-span study for Chile. Documentos de Trabajo (Banco Central de Chile), (215), 1-43.

Edison, H. J., \& Klovland, J. T. (1987). A quantitative reassessment of the purchasing power parity hypothesis: Evidence from Norway and the United Kingdom. Journal of Applied Econometrics, 2(4), 309-333.

Eickmeier, S. (2009). Comovements and heterogeneity in the euro area analyzed in a non-stationary dynamic factor model. Journal of Applied Econometrics, 24(6), 933-959.

Froot, K. A., \& Rogoff, K. (1995). Perspectives on PPP and long-run real exchange rates. Handbook of International Economics, 3, 1647-1688. 
Gailliot, H. J. (1970). Purchasing power parity as an explanation of long-term changes in exchange rates. Journal of Money, Credit and Banking, 2(3), 348-357.

Genberg, H. (1978). Purchasing power parity under fixed and flexible exchange rates. Journal of International Economics, $8(2), 247-276$.

Geary, R. C. (1958). A note on the comparison of exchange rates and purchasing power between countries. Journal of the Royal Statistical Society. Series A (General), 121(1), 97-99.

Harvey, D. I., Leybourne, S. J., \& Xiao, B. (2008). A powerful test for linearity when the order of integration is unknown. Studies in Nonlinear Dynamics \& Econometrics, 12(3), 1-23.

He, H., Chou, M. C., \& Chang, T. (2014). Purchasing power parity for 15 Latin American countries: Panel SURKSS test with a Fourier function. Economic Modelling, 36, 37-43.

Holmes, M. J. (2001). New evidence on real exchange rate stationarity and purchasing power parity in less developed countries. Journal of Macroeconomics, 23(4), 601-614.

Im, K. S., Pesaran, M. H., \& Shin, Y. (1997). Testing for unit roots in heterogeneous panels. Journal of Econometrics, $115(1), 53-74$.

Johansen, S. (1988). Statistical analysis of cointegration vectors. Journal of Economic Dynamics and Control, 12(2-3), 231-254.

Johnson, H. (1976). The monetary approach to balance-of-payments theory. The Monetary Approach to the Balance of Payment, 147-67.

Kalyoncu, H., \& Kalyoncu, K. (2008). Purchasing power parity in OECD countries: Evidence from panel unit root. Economic Modelling, 25(3), 440-445.

Kapetanios, G., Shin, Y., \& Snell, A. (2003). Testing for a unit root in the nonlinear STAR framework. Journal of Econometrics, 112(2), 359-379.

Khamis, S. H. (1970). Properties and conditions for the existence of a new type of index numbers. Sankhyā: The Indian Journal of Statistics, Series B, 81-98.

Krugman, P. R., Obstfeld, M., \& Melitz, J. M. (1988). Price levels and the exchange rate in the long run. International economics: Theory and policy (pp. 378-409). Boston (MA): Scott, Foresman, and Co.

Kwiatkowski, D., Phillips, P. C., Schmidt, P., \& Shin, Y. (1992). Testing the null hypothesis of stationarity against the alternative of a unit root: How sure are we that economic time series have a unit root? Journal of Econometrics, 54(1-3), 159-178.

Lee, C., Wu, J. L., \& Yang, L. (2016). A Simple panel unit-root test with smooth breaks in the presence of a multifactor error structure. Oxford Bulletin of Economics and Statistics, 78(3), 365-393.

Lee, J., \& Strazicich, M. C. (2004). Minimum LM unit root test with one structural break. Manuscript, Department of Economics, Appalachian State University, 33(4), 2483-2492.

Lothian, J. R., \& Taylor, M. P. (2000). Purchasing power parity over two centuries: Strengthening the case for real exchange rate stability: A reply to Cuddington and Liang. Journal of International Money and Finance, 19(5), 759764.

Lucas Jr, R. E. (1982). Interest rates and currency prices in a two-country world. Journal of Monetary Economics, 10(3), 335-359.

Ma, W., Li, H., \& Park, S. Y. (2017). Empirical conditional quantile test for purchasing power parity: Evidence from East Asian countries. International Review of Economics \& Finance, 49, 211-222.

MacDonald, R. (1993). Long-run purchasing power parity: Is it for real? The Review of Economics and Statistics, 75(4), 690-695.

MacDonald, R., \& Taylor, M. P. (1994). The monetary model of the exchange rate: Long-run relationships, short-run dynamics and how to beat a random walk. Journal of International Money and Finance, 13(3), 276-290.

Menyah, K., Nazlioglu, S., \& Wolde-Rufael, Y. (2014). Financial development, trade openness and economic growth in African countries: New insights from a panel causality approach. Economic Modelling, 37, 386-394.

Narayan, P. K. (2005). New evidence on purchasing power parity from 17 OECD countries. Applied Economics, 37(9), 1063-1071.

Nusair, S. A. (2003). Testing the validity of purchasing power parity for Asian countries during the current float. Journal of Economic Development, 28(2), 129-147. 
Ocal, O. (2013). Purchasing power parity in the case of Romania: Evidence from structural breaks. International Journal of Economics and Financial Issues, 3(4), 973-976.

Papell, D. H. (1997). Searching for stationarity: Purchasing power parity under the current float. Journal of International Economics, 43(3-4), 313-332.

Payne, J., Lee, J., \& Hofler, R. (2005). Purchasing power parity: Evidence from a transition economy. Journal of Policy Modeling, 27(6), 665-672.

Pesaran, M. H. (2004). General diagnostic tests for cross-sectional dependence in panels. Discussion Paper Series, IZA DP No. 1240.

Pesaran, M. H. (2007). A simple panel unit root test in the presence of cross-section dependence. Journal of Applied Econometrics, 22(2), 265-312.

Pesaran, M. H., Smith, L. V., \& Yamagata, T. (2013). Panel unit root tests in the presence of a multifactor error structure. Journal of Econometrics, 175(2), 94-115.

Pesaran, M. H., Ullah, A., \& Yamagata, T. (2008). A bias-adjusted LM test of error cross-section independence. The Econometrics Journal, 11(1), 105-127.

Phillips, P. C., \& Perron, P. (1988). Testing for a unit root in time series regression. Biometrika, 75(2), 335-346.

Qayyum, A., Khan, M. A., Khair-u-Zaman, \& Saqib, O. F. (2004). Exchange Rate Misalignment in Pakistan: Evidence from Purchasing Power Parity Theory [with Comments]. The Pakistan Development Review, 721-735.

Sachs, G. (2007). Beyond the BRICs: A look at the next 11. Beyond BRICS; Goldman Sachs Global Economic Group: New York, NY, USA.

Sarno, L. (2005). Towards a solution to the puzzles in exchange rate economics: Where do we stand? Canadian Journal of Economics/Revue Canadienne D'économique, 38(3), 673-708.

Strauss, J. (1995). Real exchange rates, PPP and the relative price of nontraded goods. Southern Economic Journal, 61, 991-1005.

Taylor, M. P., \& Peel, D. A. (2000). Nonlinear adjustment, long-run equilibrium and exchange rate fundamentals. Journal of international Money and Finance, 19(1), 33-53.

Taylor, A. M., \& Taylor, M. P. (2004). The purchasing power parity debate. Journal of Economic Perspectives, 18(4), 135158.

Vasconcelos, C. R. F., \& Júnior, L. A. L. (2016). Validity of purchasing power parity for selected Latin American countries: Linear and non-linear unit root tests. Economia, 17(1), 114-125.

Wilson, D., Stupnytska, A., Poddar, T., Bhundia, A., Morra, P., \& Ahmed, S. (2007). Goldman Sachs, Global Economics Paper No: 153

Wu, J. L. (1996). The empirical investigation of long-run purchasing power parity: The case of Taiwan exchange rates. International Economic Journal, 10(4), 59-69.

Xie, Z., Chen, S. W., \& Hsieh, C. K. (2021). Facing up to the polysemy of purchasing power parity: New international evidence. Economic Modelling, 98, 247-265.

Yılancı, V. (2012). The validity of purchasing power parity in Central and Eastern European countries: A rolling nonlinear unit root. Economic Research-Ekonomska Istraživanja, 25(4), 973-986.

Yıldırım, D. (2017). Empirical investigation of purchasing power parity for Turkey: Evidence from recent nonlinear unit root tests. Central Bank Review, 17(2), 39-45.

Zeren, F., \& Işlek, H. 4 Is Per Capita Real GDP Stationary in the D-8 Countries? Evidence from a Panel Unit Root Test. (Ed.) E. Çağlayan Akay \& Ö. Korkmaz, Selected topics in applied econometrics (pp. 67-86). PeterLang.

Zhou, S. (1997). Purchasing power parity in high-inflation countries: A cointegration analysis of integrated variables with trend breaks. Southern Economic Journal, 64(2), 450-467.

Zivot, E., \& Andrews, D. W. K. (2002). Further evidence on the great crash, the oil-price shock, and the unit-root hypothesis. Journal of Business \& Economic Statistics, 20(1), 25-44. 
This Page Intentionally Left Blank 